patients' confidence and trust. The concern is that those who pose the greatest danger to others, may be the ones who become most motivated to avoid contact with services.

DEPARTMENT OF HEALTH (2000) Reforming the Mental Health Act. London: Stationery Office.

TAYLOR, P. J. \& GUNN, J. (1999) Homicides by people with mental illness: myth and reality. British Journal of Psychiatry, 174, 9-14.

Santoch Rai Specialist Registrar in Forensic Psychiatry, The Hutton Centre, St Luke's Hospital, Marton Road, MiddlesbroughTS4 3AF

\section{In-patient adolescent services}

Sir: I was interested to read the report of Worrell and O'Herlihy (Psychiatric Bulletin, June 2001, 25, 219-222) summarising the views of psychiatrists on in-patient child and adolescent provision. I have completed a similar survey in Wales, with a response rate of $96 \%(25 / 26$ responses).

In Wales no psychiatrist has access to an adolescent psychiatric in-patient bed for emergency admissions. Eighty per cent $(n=20)$ usually use a bed 'borrowed' from adult services and 20\% ( $n=5)$ use paediatric beds either primarily, or equally to adult psychiatric beds.

Eighty-eight per cent $(n=22)$ believe appropriate in-patient care is delayed for adolescents with mental illness because of inadequate provision. All believe this is primarily because of insufficient beds. Sixty-eight per cent $(n=17)$ identify the lack of specialist adolescent provision, particularly adolescent psychiatric intensive care and adolescent forensic mental health provision.

Forty per cent of psychiatrists $(n=10)$ feel the regional adolescent units are frequently unable to offer a bed within an acceptable time. Those patients are managed locally in adult psychiatric (24\%) or paediatric $(16 \%)$ beds or referred out of area largely to beds within the independent sector.

The response rate of $>95 \%$ suggests the views expressed are representative of opinion in Wales. In my study higher percentages report delayed in-patient care $(88 \%$ v. 36\%) and inadequate specialist provision (68\% v. $17 \%$ ).

Regional differences in current provision may influence the level of concern expressed in Wales. My findings indicate the themes raised by Worrell and O'Herlihy are not only representative of opinion within the specialty but that experiences in Wales may be more extreme than those in England.

Pamela Duthie Specialist Registrar in Child and Adolescent Psychiatry, Ty Bryn Child and Family Service, St Cadocs Hospital, Lodge Rd, Caerleon, Gwent

\section{Mental health problems of asylum seekers}

Sir: Derek Summerfield's editorial (Psychiatric Bulletin, May 2001, 25, 161163) shows how apparent mental health problems of asylum seekers/refugees must be seen in the context of disrupted social lives, and the importance of such practical issues as employment.

One practical issue not mentioned was housing. Those with no established right of abode experience special difficulties in securing accommodation.

For the hospital, this causes a danger of bed blocking if the patient ought not be discharged without an address to allow appropriate follow-up. Normally referrals are made to social services or to the Salvation Army. However, the social services has no duty to house an illegal immigrant, and the Salvation Army cannot help as it cannot recover costs via the benefits system. The Home Office does have a duty to house immigrants whose status is being investigated. However, faced with a detention centre, the patient may withhold consent to inform the Home Office. The stand-off can persist until a stage is reached in an asylum application when the applicant becomes eligible for benefits, and can be brought into the normal support system.

Even for an experienced doctor knowing the system, the process is difficult and extremely frustrating. How much harder must this be for someone trying to deal with a foreign language. As Derek Summerfield and others (for example, see Burnett \& Peel, 2001) note, symptoms of psychological distress are common among refugees but may not signify clinical mental illness. Other cultural and social factors may contribute to psychological distress (for a recent analysis see Bhugra \& Jones, 2001). Surely, the difficulties of finding accommodation must be one such contributing factor.

BHUGRA, D. \& JONES, P. (2001) Migration and mental illness. Advances in Psychiatric Treatment, 7, 216 223.

BURNETT, A. \& PEEL, M. (2001) Asylum seekers and refugees in Britain: health needs of asylum seekers and refugees. BMJ, 322, 544-547.

AmandaThompsell Specialist Registrar in General Adult Psychiatry, Maudsley Hospital SE5 8AZ

\section{Hyperglycaemia and myoclonus with clozapine}

Sir: Hyperglycaemia and myoclonus have been reported as uncommon adverse events with clozapine treatment. We report two cases in which they occurred together in close temporal association.

\section{Case 1}

A 42-year-old African-Caribbean man with a history of severe, treatmentresistant schizophrenia developed myoclonic jerks while taking clozapine $700 \mathrm{mg} /$ day. Eight weeks later he developed diabetic ketoacidosis with a blood glucose of $44 \mathrm{mmol} / \mathrm{l}$, for which he required intensive care treatment. Clozapine treatment was subsequently stopped. Following recovery he was reinstated on clozapine, has not developed further myoclonus and his glucose tolerance is not impaired.

\section{Case 2}

A 58-year-old White British man with a history of clozapine-induced hyperglycaemia was restarted on clozapine $400 \mathrm{mg} /$ day. After 2 weeks he developed severe myoclonus and deterioration of glycaemic control with random serum glucose as high as $21.5 \mathrm{mmol} / \mathrm{l}$. Clozapine treatment was withdrawn. Within 7 days control of his blood sugar was reestablished and myoclonus resolved.

Myoclonus has been reported in $0.2 \%$ of 24000 clozapine treated patients on the UK Clozaril Patient Monitoring Service (CPMS) database. Results from case series suggest the incidence may be as high as $2.0 \%$ (Safferman et al, 1991) to $2.7 \%$ (Sajatovic \& Meltzer, 1996).

Impaired glucose tolerance with clozapine treatment is also probably more common than the $0.4 \%$ quoted by the UK CPMS (Linda Annan, Advisor, CPMS, personal communication). In a case-note study of 82 patients, $36.6 \%$ were considered to have developed diabetes (Henderson et al, 2000). The true prevalence of these adverse events remains to be established.

The association between hyperglycaemia and movement disorders, including myoclonus, has been well documented (Moores \& Dire, 1989). Hyperglycaemia is the commonest metabolic disorder to be associated with clonic activities of the extremities and other focal motor phenomena. Correction of the underlying metabolic disturbance prevents further focal seizures or movement abnormalities (Berkovic et al, 1982).

Since uncontrolled hyperglycaemia is potentially life threatening, the presence of myoclonus in clozapine treated patients may be of use in alerting clinicians to the presence of impaired glucose tolerance.

BERKOVIC, S., JOHNS, J. \& BLADIN, P. (1982) Focal seizures and systemic metabolic disorders. Australian and New Zealand Journal of Medicine, 12, 620-623.

HENDERSON, D., CAGLIERO, E., GRAY, C., et al (2000) Clozapine, diabetes mellitus, weight gain, and lipid abnormalities: a five year naturalistic study. American Journal of Psychiatry, 157, 975-981. 